\title{
Assessment of Patient' Relatives Satisfaction Towards Health Service Delivery in Tertiary Health Facilities in Benin-City, Edo State, Nigeria
}

\author{
Esohe Olivia Ogboghodo*, Adedoyin Catherine Adeniyi, Obehi Hilda Okojie \\ Department of Community Health, College of Medical Sciences, University of Benin, Benin City, Nigeria
}

Email address:

oliviadynski@yahoo.com (E. O. Ogboghodo)

${ }^{*}$ Corresponding author

\section{To cite this article:}

Esohe Olivia Ogboghodo, Adedoyin Catherine Adeniyi, Obehi Hilda Okojie. Assessment of Patient' Relatives Satisfaction Towards Health Service Delivery in Tertiary Health Facilities in Benin-city, Edo State, Nigeria. Central African Journal of Public Health. Vol. 5, No. 4, 2019, pp. 178-184. doi: 10.11648/j.cajph.20190504.17

Received: June 5, 2019; Accepted: July 12, 2019; Published: July 26, 2019

\begin{abstract}
This study aims to assess satisfaction rate of patient's relatives towards health service delivery in tertiary health facilities in Benin City, Edo State, Nigeria. A descriptive cross-sectional study design among patient's relatives was carried out. Data collection was by mixed methods using a pre-tested, interviewer-administered questionnaire and Focus Group Discussion Guide. Quantitative data collected was analyzed using IBM SPSS version 22.0 while qualitative data was analyzed thematically using ATLAS. ti software. Logistic regression was used to calculate the determinants of satisfaction of respondents with their corresponding odds ratios (OR), 95\% confidence intervals $(\mathrm{CI})$, and p-values recorded. The level of significance was set at $\mathrm{p}<0.05$. A total number of 412 respondents (comprising 400 respondents and 12 Focus Group Discussion participants) were surveyed. The study showed a higher proportion 228 (57.0\%) of respondents with dissatisfaction. The determinants of satisfaction of HSD were; sex (OR: 5.976 95\% CI: 1.147-3.465), skill level (OR: 7.276 95\% CI: 0.1490.740 ) and being on NHIS (OR: 5.442 95\% CI: 0.193-0.867). Thematic analysis of the FGD revealed that poor communication, high cost of service, lack of empathy demonstrated by some health workers and prolonged stay on admission were reasons for dissatisfaction. A higher proportion of the respondents had overall dissatisfaction with HSD and factors such as timeliness, cost of service and lack of empathy demonstrated by health care workers were identified as reasons for the dissatisfaction.
\end{abstract}

Keywords: Satisfaction, Health Service Delivery, Tertiary Health Facilities

\section{Introduction}

Patient satisfaction is an emerging issue that is of importance both to medical (health) care providers, the patients (consumers) themselves and other third-party stakeholders (e.g. the patients relatives) in the medical care industry. [1] The tertiary hospitals in Nigeria are often seen as authorities in several issues relating to health thereby creating high expectations concerning quality of care in the society. [2] In the tertiary hospital organization, several factors such as patients-related, employee-related and employer-related factors interact to affect the quality of care the patients received. [2, 3] Quality of health services was traditionally based on professional practice standards, however over the last decade; patient's perception about healthcare has been predominantly accepted as an important indicator for measuring quality of health care and a critical component of performance, improvement and clinical effectiveness. [4, 5] Patient Satisfaction is one of the essential indicators for healthcare service improvement. From that view, the patient satisfaction survey is an instrument in monitoring health care delivery of a hospital in relation to cost and services. [6, 7] Thus, assessing patient satisfaction can bring new changes in approach or modification in various aspect of care. [8,9]

Information about patient's and significant others' subjective experience contributes to the establishment and maintenance of therapeutic interventions. [10] The attitude and behavior of the doctors and the nurses towards the patients appears to be a key factor in perceived quality of care, and whether the patients can 
successfully cope with the stress of their hospitalization experience. [11-13] Various dimensions of patient satisfaction have been identified, ranging from admission to discharge services, as well as from medical care to interpersonal communication. Well recognized criteria include responsiveness, communication, attitude, clinical skill, comforting skill, amenities, food services, etc. It has also been reported that the interpersonal and technical skills of health care provider are two unique dimensions involved in patient assessment of hospital care. [14] Patients and families are expressing a desire for a larger role in healthcare decision making and are asking providers to do a better job of responding to patient and family needs. Despite these concerns, families and other surrogates often feel uninformed and disenfranchised from clinical decision making and day-to-day care of loved ones. [15] The attitude of health care workers to the patient and their relatives are often described as lacking of empathy especially in developing countries where the health care worker is overworked. The attitude of the health worker to a long extent impedes access to health care and health care service delivery satisfaction. [15]

The patient relatives play an important role in assessing service delivery as they are involved in major and diverse roles such as payment for health services, caring for the patient etc. that ensures the patient's health is restored. Thus, this study focus on patient's relatives as they experience the stress of caring for a loved one and are also involve in several steps of service delivery in the hospital setting as they run errands while caring for a sick relative in the hospital setting. Assessment of health service delivery has implication for decisions on effective monitoring of the entire health system towards enhancing quality health care service delivery which would enhance patients as well as their caregiver satisfaction.

\section{Methods}

The study was carried out among the relatives of the inpatient in the tertiary health facilities in Benin City. Benin City is home to 3 tertiary facilities which include; University of Benin Teaching Hospital, Federal Neuro-psychiatric Hospital (FNPH) and Stella Obasanjo Women and Children Hospital. [16-19]

A descriptive cross-sectional study design using mixed method was utilized for this study and the study population comprised in-patient's relatives of tertiary hospitals in Benin City who are in charge of caring for them. The sample size was calculated using the formula for single proportion [20] where $p$ was the percentage of patient relative's satisfaction level. [6] A multistage sampling technique was used in the course of the study to select 400 respondents from 2 tertiary health facilities viz. UBTH and FNPH.

Quantitative and qualitative tools were used for data collection. A structured questionnaire with open and closed ended questions was used to collect data. The questionnaire focused on assessing the respondent's socio-demographic characteristics, their satisfaction rates and determinants of satisfaction. The qualitative tool was a focused group discussion guide which was designed in line with the specific objectives. The questionnaire was interviewer-administered to the respondents in a conducive environment which would promote maximum cooperation. A FGD involving 12 participants was used in the study and care was taken to avoid systematic bias and friendship groups and this was done by randomly selecting participants.

The FGDs took place at one of the tertiary health facility selected and participants were briefed on the purpose of the discussion and were encouraged to air their views. The discussion was guided by the researcher such that the discussion was not dominated by a set of participants. Notes were taken during the discussion and audio recording was also done and transcribed to corroborate the information missed during note taking. [21] The discussion was conducted in English. The discussion lasted for 30 minutes and at the end of the discussion, participants were educated on their health rights.

All data were retrieved, sorted, screened for completeness, coded and analyzed using IBM SPSS version 22.0 and ATLAS.ti for quantitative and qualitative data, respectively. The occupation of respondents were coded based on the ILO classification [22] which was modified for the purpose of this study into skill levels $0,1,2,3$ and 4 where skill level 0 comprised the unemployed and students.

Satisfaction was scored using the three point likert's scale. A total of 8 questions was used to assess satisfaction with a maximum score of 2 for satisfied, 1 for undecided and 0 for unsatisfied, making an overall score of 16 . A score of $0-8$ was regarded as unsatisfied while a score of $9-16$ was regarded as satisfied. Univariate analysis was done to assess the distribution of the variables. Bivariate analysis was also done to determine association between socio-demography of respondents with their satisfaction rate. Logistic regression on determinants of satisfaction was also done to determine the odds of a determinant on the outcome.

Data from the FGD was analysed using the ATLASti Vs 6.0. Data was sorted and classified according to research objectives and translation to English Language was carried out. Themes were interpreted and elaborated on to produce the findings of the data in line with the objectives of the study. Ethical approval to conduct this research was sought and obtained from The University of Benin Teaching Hospital Ethics and research committee. Informed consent was taken from the respondents before administering questionnaires or undertaking the focus group discussion. Names and addresses were omitted to ensure confidentiality.

\section{Results}

The mean age of respondents was $30.6 \pm 11.3$ years with a greater proportion $180(45.0 \%)$ belonging to the age group $20-29$ years. Majority $208(52.0 \%)$ of the respondents were married. The predominant religion was Christianity 376 (94.0\%) and a higher proportion 250 (62.5\%) of the respondents had tertiary level of education. Respondents 
earning $<20,000$ naira constituted the majority $140(35.0 \%)$. A greater proportion $304(76.0 \%)$ of the respondents' relatives were not on NHIS. (Table 1)

Table 1. Socio-demographic and socio-economic characteristics of respondents.

\begin{tabular}{|c|c|c|}
\hline Variables & Frequency $(n=400)$ & Percent \\
\hline \multicolumn{3}{|l|}{ Age group (years) } \\
\hline$<20$ & 54 & 13.5 \\
\hline $20-29$ & 180 & 45.0 \\
\hline $30-39$ & 82 & 20.5 \\
\hline $40-49$ & 58 & 14.5 \\
\hline$>50$ & 26 & 6.5 \\
\hline Mean (SD) & $30.6(11.3)$ & \\
\hline \multicolumn{3}{|l|}{ Sex } \\
\hline Female & 236 & 59.0 \\
\hline Male & 164 & 41.0 \\
\hline Marital status & 208 & 52.0 \\
\hline Single & 172 & 43.0 \\
\hline Married & 6 & 1.5 \\
\hline Divorced & 6 & 1.5 \\
\hline Widowed & 4 & 1.0 \\
\hline Separated & 4 & 1.0 \\
\hline \multicolumn{3}{|l|}{ Cohabiting } \\
\hline \multicolumn{3}{|l|}{ Level of education } \\
\hline No formal education & 4 & 1.0 \\
\hline Primary & 12 & 3.0 \\
\hline Secondary & 134 & 33.5 \\
\hline Tertiary & 250 & 62.5 \\
\hline \multicolumn{3}{|l|}{ Religion } \\
\hline Christianity & 376 & 94.0 \\
\hline Islam & 22 & 5.5 \\
\hline ATR & 2 & 0.5 \\
\hline \multicolumn{3}{|c|}{ Average monthly income (Naira) } \\
\hline$<20,000$ & 140 & 35.0 \\
\hline $20,000-40,000$ & 110 & 27.5 \\
\hline $41,000-60,000$ & 66 & 16.5 \\
\hline $61,000-80,000$ & 32 & 8.0 \\
\hline $81,000-100,000$ & 34 & 8.5 \\
\hline$>100,000$ & 18 & 4.5 \\
\hline \multicolumn{3}{|l|}{ Patient on NHIS } \\
\hline No & 304 & 76.0 \\
\hline Yes & 96 & 24.0 \\
\hline
\end{tabular}

Majority $182(45.5 \%)$ of the respondents were satisfied with accessibility of health service while a lower proportion $54(13.5 \%)$ were undecided about their satisfaction and 164 $(41.0 \%)$ were unsatisfied with accessibility. A higher proportion $178(44.5 \%), 170(42.5 \%), 226(56.5 \%)$ and 166 $(41.5 \%)$ of the respondents were satisfied with staff courtesy, perception of quality care, communication about patient's condition and procedure to be done, and food services respectively while a higher proportion $222(55.5 \%)$ and 174 $(43.5 \%)$ were unsatisfied with cost of service, and time taken to receive service. An equal proportion 166 (41.0\%) were either satisfied or unsatisfied with comforting skills of health care workers while $72(18.0 \%)$ were undecided about their satisfaction stance. Communication about patient's condition and procedures to be done had the highest proportion 226 $(56.5 \%)$ of satisfaction among respondents while cost of service had the highest proportion of dissatisfaction among the respondents. (Table 2)

Table 2. Satisfaction rate of respondents towards health service delivery.

\begin{tabular}{llll}
\hline Variable & $\begin{array}{l}\text { Satisfied } \\
\text { Freq (\%) }\end{array}$ & $\begin{array}{l}\text { Undecided } \\
\text { Freq (\%) }\end{array}$ & $\begin{array}{l}\text { Unsatisfied } \\
\text { Freq (\%) }\end{array}$ \\
\hline $\begin{array}{l}\text { Accessibility to } \\
\text { health facility }\end{array}$ & $182(45.5)$ & $54(13.5)$ & $164(41.0)$ \\
$\begin{array}{l}\text { Staff courtesy } \\
\begin{array}{l}\text { Perceived quality of } \\
\text { care }\end{array}\end{array}$ & $178(44.5)$ & $68(17.0)$ & $154(38.5)$ \\
$\begin{array}{l}\text { Cost of service } \\
\begin{array}{l}\text { Communication } \\
\text { about patient's }\end{array}\end{array}$ & $124(31.0)$ & $54(13.5)$ & $222(55.5)$ \\
$\begin{array}{l}\text { condition and } \\
\text { procedures to be done }\end{array}$ & $226(56.5)$ & $70(17.5)$ & $104(26.0)$ \\
$\begin{array}{l}\text { Comforting skills } \\
\begin{array}{l}\text { Food services } \\
\text { Time taken to receive } \\
\text { service }\end{array}\end{array}$ & $164(41.0)$ & $72(18.0)$ & $164(41.0)$ \\
\hline
\end{tabular}

A higher proportion $228(57.0 \%)$ of the respondents had overall dissatisfaction with health service while a lower proportion $172(43.0 \%)$ of respondents had overall satisfaction.

The age of the respondents was found to be significantly $(p=0.008)$ associated with respondents' satisfaction rate. Other socio-demographic characteristics that were significant were; marital status of the respondent $(p=0.015)$, level of education $(\mathrm{p}=0.046)$ and religion of the respondents $(\mathrm{p}=$ 0.004). The sex of the respondents was found not to be statistically significant to satisfaction rate of the respondents with a $\mathrm{p}$ value of 0.125 . (Table 3 )

Table 3. Socio-demographic characteristics and satisfaction rate of respondents towards hsd.

\begin{tabular}{|c|c|c|c|}
\hline \multirow{2}{*}{ Variables } & \multicolumn{2}{|l|}{ Overall satisfaction } & \multirow{2}{*}{$\begin{array}{l}\text { Total }(n=400) \\
(\text { Freq \%) }\end{array}$} \\
\hline & Satisfied $(n=172)($ Freq $\%)$ & Unsatisfied $(n=228)($ Freq \%) & \\
\hline \multicolumn{4}{|l|}{ Age group (years) } \\
\hline$<20$ & $28(51.9)$ & $26(48.1)$ & $54(100.0)$ \\
\hline $20-29$ & $68(37.8)$ & $112(62.2)$ & $180(100.0)$ \\
\hline $30-39$ & $30(36.6)$ & $52(63.4)$ & $82(100.0)$ \\
\hline $40-49$ & $36(62.1)$ & $22(37.9)$ & $58(100.0)$ \\
\hline$>50$ & $10(38.5)$ & $16(61.5)$ & $26(100.0)$ \\
\hline \multicolumn{4}{|l|}{$\chi^{2}=13.929 \mathrm{P}$ value $=0.008$} \\
\hline \multicolumn{4}{|l|}{ Sex } \\
\hline Male & $78(47.6)$ & $86(52.4)$ & $164(100.0)$ \\
\hline Female & $94(39.8)$ & $142(60.2)$ & $236(100.0)$ \\
\hline $\begin{array}{l}\chi^{2}=2.359 \mathrm{P} \text { value }=0.125 \\
\text { Marital status }\end{array}$ & & & \\
\hline
\end{tabular}




\begin{tabular}{llll}
\hline \multirow{2}{*}{ Variables } & Overall satisfaction & & $\begin{array}{l}\text { Total }(\mathbf{n}=\mathbf{4 0 0}) \\
\text { (Freq \%) }\end{array}$ \\
\cline { 2 - 3 } & Satisfied $(\mathbf{n}=\mathbf{1 7 2})$ (Freq \%) & Unsatisfied (n= 228) (Freq \%) & $208(100.0)$ \\
Single & $80(38.5)$ & $128(61.5)$ & $172(100.0)$ \\
Married & $82(47.7)$ & $90(52.3)$ & $6(100.0)$ \\
Divorced & $2(33.3)$ & $4(66.7)$ & $6(100.0)$ \\
Widowed & $4(66.7)$ & $2(33.3)$ & $4(100.0)$ \\
Separated & $4(100.0)$ & $0(0.0)$ & $4(100.0)$ \\
Cohabiting & $0(0.0)$ & $4(100.0)$ & \\
Fisher's Exact Test $=12.481$ P value $=0.015$ & & & $4(100.0)$ \\
Level of education & & $4(100.0)$ & $12(100.0)$ \\
No formal education & $0(0.0)$ & $4(33.3)$ & $134(100.0)$ \\
Primary & $8(66.7)$ & $70(52.2)$ & $250(100.0)$ \\
Secondary & $64(47.8)$ & $150(60.0)$ & \\
Tertiary & $100(40.0)$ & & $376(100.0)$ \\
Fisher's Exact Test $=7.509$ P value $=0.046$ & & $220(58.5)$ & $22(100.0)$ \\
Religion & & $6(27.3)$ & $2(100.0)$ \\
Christianity & $156(41.5)$ & $2(100.0)$ & \\
Islam & $16(72.7)$ & & \\
ATR & $0(0.0)$ & & \\
Fisher's Exact Test $=9.255$ P value $=0.004$ & & & \\
\hline
\end{tabular}

Skill level 1 accounted for a larger proportion $8(80.0 \%)$ of respondents who were satisfied while skill level 3 accounted for a larger proportion $10(83.3 \%)$ of respondents who are unsatisfied. The association between skill level and satisfaction rate was statistically significant $(\mathrm{p}=<0.001)$. A higher proportion $20(58.8 \%)$ of respondents who were satisfied earn an average monthly income of 81,000 100,000 naira while a higher proportion $82(74.5 \%)$ of respondents who were unsatisfied earn an average monthly income between 20,000-40,000 naira. There was a statistical significant association $(\mathrm{p}=<0.001)$ between average monthly income of respondents and satisfaction. (Table 4).

Table 4. Socioeconomic characteristics and satisfaction rate of respondents towards health service delivery.

\begin{tabular}{|c|c|c|c|}
\hline \multirow{2}{*}{ Variables } & \multicolumn{2}{|l|}{ Overall satisfaction } & \multirow{2}{*}{$\begin{array}{l}\text { Total }(n=400) \\
(\text { Freq \%) }\end{array}$} \\
\hline & Satisfied $(n=172)($ Freq $\%)$ & Unsatisfied $(n=228)($ Freq \%) & \\
\hline \multicolumn{4}{|l|}{ Skill level } \\
\hline Skill level 0 & $46(31.9)$ & $98(68.1)$ & $144(100.0)$ \\
\hline Skill level 1 & $8(80.0)$ & $2(20.0)$ & $10(100.0)$ \\
\hline Skill level 2 & $66(45.8)$ & $78(54.2)$ & $144(100.0)$ \\
\hline Skill level 3 & $2(16.7)$ & $10(83.3)$ & $12(100.0)$ \\
\hline Skill level 4 & $50(55.6)$ & $40(44.4)$ & $90(100.0)$ \\
\hline \multicolumn{4}{|c|}{$\begin{array}{l}\text { Fisher's Exact Test }=22.225 \text { P value }=<0.001 \\
\text { Average monthly income (Naira) }\end{array}$} \\
\hline$<20,000$ & $66(47.1)$ & $74(52.9)$ & $140(100.0)$ \\
\hline $20,000-40,000$ & $28(25.5)$ & $82(74.5)$ & $110(100.0)$ \\
\hline $41,000-60,000$ & $36(54.5)$ & $30(45.5)$ & $66(100.0)$ \\
\hline $61,000-80,000$ & $12(37.5)$ & $20(62.5)$ & $32(100.0)$ \\
\hline $81,000-100,000$ & $20(58.8)$ & $14(41.2)$ & $34(100.0)$ \\
\hline$>100,000$ & $10(55.6)$ & $8(44.4)$ & $18(100.0)$ \\
\hline
\end{tabular}

Age of the respondents was a significant predictor of satisfaction $(p<0.05)$. With an increase in respondents' level of education, satisfaction was likely to be decreased. (OR: 0.001 , CI: $0.001-0.001$ ). Having health insurance (NHIS) decreased level of satisfaction by 0.894 . This was more likely by an odds ratio of 5.442. This was however statistically significant $(\mathrm{p}=0.020, \mathrm{CI}=0.193-0.867)$. Having good knowledge decreased the level of satisfaction by 0.573 . This was more likely by an odds ratio of 2.193 . This was however not statistically significant $(\mathrm{p}=0.139)$. Having a positive attitude also was found to decrease the level of satisfaction by 3.828 . This was more likely by an odds ratio of $78.199(p=0.01, C I=0.009-0.051)$. (Table 5)

The Focus Group Discussion revealed varied and diverse perceptions of respondents on the determinants of satisfaction of health service delivery. Respondents were satisfied to an extent with health service delivery but were however not satisfied in some instances because of factors such as poor communication, high cost of service, lack of empathy demonstrated by some health workers and prolonged stay on admission. Health insurance schemes was not seen by most of the respondents as a means to lessen the cost of service as the scheme does not cover areas that are even more expensive to afford.

'I think the health care service is ok but the cost of service is too much although they treat patient well o but the queue can get too much at times'.

37 year old male

I agree that the cost is expensive, also the health worker too need to learn how to talk to us, both the relatives and patients about the drugs or test that is to be done as some will keep pricking my child without telling me why, they need 
to learn mannerism. The way some of them even address one who is going through pain does not show any sense of humanity at all'.

39 year old female

'We are sometimes asked to buy some drugs which are not available in the hospital outside. We are also sometimes referred to do our tests in other hospitals especially the private ones and these ones are very expensive. This does not depict good standard for a tertiary health facility, they should be the go to people not the other way round'.

33 year old female

'Being on NHIS does not even seem to be helping reduce the cost of service as expensive procedures are not being covered by NHIS. The longer one even spends on admission the more expenses one tend to make and all these are factors that causes disastifacttion'.

42 year old male

\section{Discussion}

The present study attempted to assess the satisfaction rate of the patient's relatives with health service delivery in tertiary hospital in Benin City, Nigeria. The results of the study indicated that most of the respondents interviewed were dissatisfied with the services they received. Very few similar studies have been done thus data for comparison is lacking. However, the findings of the survey are quite helpful if they are acted upon to improve quality of health service. Measuring patient satisfaction has several purposes but there are three prominent reasons to do so. Such interviews help to evaluate health care services from the client's point of view, facilitate the identification of problem areas and help generate ideas towards resolving these problems. [4] The fact that respondents expressed dissatisfaction with the services indicates that hospital administration needs to do more in the drive towards improving services.

Majority of the respondents were satisfied with varied aspect of HSD such as accessibility to health facility, staff courtesy, perception of quality of care, communication about patient's condition and procedure to be done and food services. This is similar to a work done in Cambodia in 2012 to assess patient satisfaction. Findings from the study revealed satisfaction in most areas of service delivery in the health facility studied. [6] A higher proportion of respondents had overall dissatisfaction while a lower proportion of respondents had overall satisfaction. A higher rate of dissatisfaction may be due to various factors such as timeliness in receiving care and cost of services as these factors record a higher proportion of dissatisfaction. This level of satisfaction appears surprising as one would ordinarily expect a higher level of satisfaction with care received at a tertiary health facility because of the available expertise, technology and sophisticated procedures that can be obtained. This finding however, demonstrates that health care quality is not simply connected with sophistication of the technologies or procedures applied but in the capacity of health interventions by the health care worker to achieve goals that meet the expectation of their clients.

Factors such as poor communication, high cost of service and lack of empathy demonstrated by some health care workers were found to be associated with high rate of dissatisfaction among respondents during the FGD. These findings are similar to a work done in Nigeria in 2014 where similar factors were found to be associated with high rate of dissatisfaction. [1] Health care worker needs to work on these areas to improve satisfaction and thus health care delivery as a whole as with improve satisfaction there is a likelihood that individuals will want to seek health care services when it is required in future. Majority of the respondents earn an average monthly income less than 20,000 naira. This may be because majority of the respondents were students. Findings from the work also revealed that a higher proportion of respondents who were not on NHIS were dissatisfied. A survey done in Nigeria demonstrating that a higher proportion of health care financing comes from out of pocket expenditure. [23] Increased rate of out of pocket expenditure for health care financing contribute to the client's burden and thus impedes satisfaction and to a large extent, health seeking behaviour. $[23,24]$ The government thus need to put in more efforts in order to improve coverage of health insurance schemes so that a larger proportion of the populace can access healthcare.

The respondent's socio-demographic and socio-economic characteristics were considered in comparing results from this survey as these characteristics to a large extent determine their satisfaction. Some may be satisfied with average services, while other may be dissatisfied even with the best. Thus this was considered in analysis and interpretation. The survey was done in a way to avoid error and bias by using appropriate tests and using scientific method of selection respectively.

\section{Conclusion}

In conclusion, a higher proportion of the respondents had overall dissatisfaction with HSD and factors such as timeliness, cost of service and lack of empathy demonstrated by health care workers were identified as reasons for the dissatisfaction. Thus the determinants of satisfaction should be emphasized as action points in key intervention programmes to improve health service delivery. The health facilities may need to employ more staff to cater to the needs of the patients so that they can be attended to in time. Health care workers also need to be more efficient in working with their clients so as not to keep their patients waiting. They should also pay more attention to the emotional and psychological needs of their patients and their relatives. The government can help in the aspect of cost of service by providing financial backing and support to the available health services so that they can function optimally and to make health service affordable. Programmes such as the NHIS should be made available to everyone and to cover health costs so that access to health care for all is ensured and health services are affordable. 
What is already known on this topic:

1. Various dimensions of patient satisfaction have been identified, ranging from admission to discharge services, as well as from medical care to interpersonal communication.

2. Information about patient's and significant others' subjective experience, that is assessing their satisfaction can serve as a means of improving health service delivery.

3. Quality of health services was traditionally based on professional practice standards, however over the last decade; patient's perception about healthcare has been predominantly accepted as an important indicator for measuring quality of health care.

What this study adds:

1. Patients' relatives are the best assessor of satisfaction rate of health service delivery as they are the caregiver of the sick patients and are also involved in the various process of patients' care.

2. Timeliness, cost of service and lack of empathy demonstrated by health care workers were identified as reasons for the dissatisfaction by patients' relatives

3. Programmes such as the NHIS and other determinants of satisfaction should be addressed to cover health costs and to ensure access to quality health services.

\section{Competing Interests}

The authors declare that they have no competing interest.

\section{Authors' Contribution}

EOO: conception, design, statistical analysis, manuscript drafting for intellectual content.

ACA: design, data collection, statistical analysis.

OHO: conception, design, revising of manuscript for intellectual content and final approval of manuscript.

\section{Acknowledgements}

The authors wish to acknowledge the research assistants and the respondents who participated in this study.

\section{References}

[1] Ofili OU. Patient satisfaction in healthcare delivery - a review of current approaches and methods. European Scientific Journal. 2014; 10 (25): 25-39.

[2] Iloh GUP, Ofoedu JN, Njoku PU, Okafor GOC, Amadi AN and Godswill-Uko EU. Satisfaction with Quality of Care Received by Patients without National Health Insurance Attending a Primary Care Clinic in a Resource-Poor Environment of a Tertiary Hospital in Eastern Nigeria in the Era of Scaling up the Nigerian Formal Sector Health. Annals of Medical and Health Science Research. 2013; 3 (1): 31-37.

[3] Mosadeghrad AM. Factors influencing healthcare service quality. Int J Health Policy Manag. 2014; 3 (2):77-89.
Published 2014 Jul 26. doi:10.15171/ijhpm.2014.65.

[4] Qadri SS, Pathak R, Singh M, Ahluwalia SK, Saini S, Garg PK. An Assessment of Patients Satisfaction with Services Obtained From a Tertiary Care Hospital in Rural Haryana. International Journal of Collaborative Research on Internal Medicine \& Public Health. 2012; 4 (8): 15241537.

[5] Aghamollaei T, Zare SH, Bodat A. Patients perception and expectation about healthcare services in Bandarabas healthcare centres. Journal of Hormozgan University of Medical Sciences. 2007; 11: 173-8.

[6] Vadhana M. Assessment of patient satisfaction in an outpatient department of an autonomous hospital in phnom penh, Cambodia. Thesis Presented to the Higher Degree Committee of Ritsumeikan Asia Pacific University. 2012.

[7] Prakash B. Patient satisfaction. J Cutan Aesthet Surg. 2010; 3 (3):151-155. doi:10.4103/0974-2077.74491.

[8] Rajeswari T. A Study to assess patient's satisfaction with quality of nursing care. Sree Chitra Tirunal Institute For Medical Sciences And Technology, Trivandrum. 2011.

[9] Groene O. Patient centredness and quality improvement efforts in hospitals: rationale, measurement, implementation, International Journal for Quality in Health Care, $2011 ; 23$ (5): 531-537. https://doi.org/10.1093/intqhe/mzr058

[10] Poulsen I, Holm S, Schonberger M, Caetano C. Patients' and relatives' experience of difficulties following severe traumatic brain injury: The sub-acute stage. Neuropsychological Rehabilitation. 2009; 19 (3): 444-460.

[11] Rokach A, Miller Y, Shick S, Abu R, Matot I. Surgery and Caregiving: Loneliness of the Patients and Those Who Care for Them. Open Journal of Medical Psychology. 2014; 3: 222234.

[12] Kieft RA, de Brouwer BB, Francke AL, Delnoij DM. How nurses and their work environment affect patient experiences of the quality of care: a qualitative study. BMC Health Serv Res. 2014; 14: 249. Published 2014 Jun 13. doi: 10.1186/1472-6963-14-249.

[13] Rokach A, Parvini M. Experience of adults and children in hospitals Early Child Development and Care. 2011; 181 (5): 707-715.

[14] Davidson JE, Powers K, Hedayat KM, Tieszen M, Kon AA, Shepard E et al. Clinical practice guidelines for support of the family in the patient-centered intensive care unit: American College of Critical Care Medicine Task Force 2004 - 2005. Lippincott Williams \& Wilkins. 2007; 35 (2): 605-622.

[15] Saha D, Sinha R, Bhavsar K. Understanding job stress among healthcare staff. Online Journal of Health and Allied Sciences. 2011; 10 (1): 1-4.

[16] Encyclopedia Britannica. Benin city In: Edo state, Nigeria. 1996. Available from: www.britannica.com. Accessed on 2019 Jun 30 at $3: 15 \mathrm{pm}$.

[17] University of Benin Teaching Hospital. About Us [Internet]. 2017. Available from: http://www.ubth.org. Accessed on 2019 Jun 30 at 3:30pm. 
[18] Federal Neuro-Psychiatric Hospital Benin city. In-Patient Facilities. In: General adult psychiatric services. [Internet]. 2017. Available at: www.psychospitaluselu.com. Accessed on 2019 Jun 30 at 4:00pm.

[19] Stella Obasanjo Hospital. About Us [Internet]. 2016. Available at: Http://medpages.info. Accessed on 2019, Jun 30 at $4: 10 \mathrm{pm}$.

[20] Suresh KP, Chandrashekara S. Sample size estimation and power analysis for clinical research studies. J Hum Reprod Sci 2012; 5: 7-13.

[21] Tynan AC, Drayton JL. Conducting Focus Groups- A guide for first time users. Marketing Intelligence \& Planning. 1988; 6 (1): 5-9.
[22] International Labour Office. International Standard Classification of Occupations Structure, group definitions and correspondence tables. 2012.

[23] Uzochukwu B, Ughasoro M, Etiaba E, Okwuosa C, Envuladu $\mathrm{E}$, Onwujekwe $\mathrm{O}$. Health care financing in Nigeria: Implications for achieving universal health coverage. Nigerian Journal of Clinical Practice. 2015; 18 (4): 437-444.

[24] Laokri S, Soelaeman R, Hotchkiss DR. Assessing out-ofpocket expenditures for primary health care: how responsive is the Democratic Republic of Congo health system to providing financial risk protection?. BMC Health Serv Res. 2018; 18 (1): 451. 